\title{
Detection of high risk human papillomavirus in routine cervical smears: Strategy for screening
}

\author{
C S Herrington, $M$ de Angelis, M F Evans, G Troncone, J O'D McGee
}

\begin{abstract}
Aim: To develop a methodology for direct detection of high risk human papillomavirus (HPV) infection in routine cervical smears by non-isotopic in situ hybridisation (NISH) which can be compared with cytopathological assessment of the same cells.

Methods: The methodology was established using cultured cells and routine cervical smears hybridised with digoxigenin labelled probes for HPV, 16, 18, 31, and 33. The technique was applied to the analysis of 53 patients from a sexually transmitted disease clinic.
\end{abstract}

Results: The optimal sensitivity achieved for single HPV detection in cultured cells was 1-2 copies of HPV 16 per cell and that for detection of a cocktail of HPV types in routine cervical smears was 2.5-12 copies per cell. Of parallel smears taken from patients with a normal Papinacolau-stained smear $33.3 \%$ (24) contained a HPV 16, 18, 31, and 33 signal indicating an occult HPV infection. The prevalence of these HPV types was similar in women in whom a cytopathological diagnosis of wart virus infection was made $(64.7 \%, 17)$ and in patients with mild dyskaryosis $(75 \%, 12)$. Conclusions: The methodology evolved localises HPV sequences directly to epithelial cell nuclei, which can be morphologically assessed by haematoxylin counterstaining. Sample contamination with exogenous viral sequences can be distinguished from true infection. In this study, a HPV signal was not found in morphologically normal epithelial cells. The methods described will permit the detection of HPV sequences in routinely collected cervical smears and the evaluation of the natural history and potential clinical relevance of HPV infection without changes in clinical practice.

The experimental evidence linking human papillomaviruses (HPV) with cervical neoplasia is strong. ${ }^{1}$ Clinically, certain HPV types, particularly HPV6 and 11, have been associated with low grade clinical lesions and a negligible risk of progression to invasive malignancy. Conversely high grade clinical lesions are associated with a different spectrum of HPV types, particularly HPV16, 18, and related viral type: ${ }^{2}$ these types are an established risk factor for clinical progression. ${ }^{3}$ Recently the association between HPV and cervical neoplasia has been questioned because HPV sequences are demonstrable using the polymerase chain reaction (PCR) in cervical samples from a high proportion of normal women. ${ }^{4-12}$ However, interpretation of the data has been problematic due to inconsistencies in methodology and results from different laboratories. Estimates of the prevalence of HPV infection in both normal and abnormal cervical epithelial cells have varied widely. ${ }^{4-12}$ The possibility of contamination with exogenous HPV sequences is difficult to exclude when methods are used which require destruction of cellular morphology. In situ hybridisation has the advantage that cellular localisation of sequences can be performed microscopically and it excludes the possibility of contamination. Isotopic detection of HPV in cervical smears has been previously described ${ }^{13}$ and non-isotopic in situ hybridisation (NISH) has been performed on cell samples collected by cervicovaginal lavage. ${ }^{14}$ These methods are not, however, applicable to cervical smears collected in the routine way.

\section{Methods}

PROBES

Genomic probes for HPV $6,11^{15}, 16,18^{16}, 31$, and $33^{17}$ were labelled with biotin and digoxigenin by nick translation as previously described. ${ }^{18}$ Total human DNA was labelled with digoxigenin and used as a positive control. ${ }^{19}$

\section{COLLECTION OF SPECIMENS}

Samples were obtained from the sexually transmitted diseases (STD) clinic in Oxford. Two standard smears were taken: one for cytopathological diagnosis and the other for NISH analysis. Smears were fixed in $70 \%$ ethanol/Carbowax in the conventional way. Cytopathological assessment was performed independently of NISH on a Papinacolaustained smear. Conventional criteria for the diagnosis of wart virus infection and cervical intraepithelial neoplasia were employed. ${ }^{20}$

\section{Pretreatment of cervical smears}

Routine smears were incubated in methanol/ acetic acid $(3: 1, v / v)$ for 10 minutes at $22^{\circ} \mathrm{C}$ and then fixed in fresh $4 \%$ paraformaldehyde $(\mathrm{w} / \mathrm{v})$ in phosphate buffered saline (PBS: $10 \mathrm{mM}$ phosphate, $150 \mathrm{mM} \mathrm{NaCl}, \mathrm{pH} \mathrm{7.4)}$ for 15 minutes at $22^{\circ} \mathrm{C}$. After washing in PBS containing $0.2 \%(\mathrm{w} / \mathrm{v})$ glycine, smears were rinsed in PBS and endogenous peroxidase
Correspondence to: J O'D McGee 
activity blocked with $0 \cdot 1 \%(\mathrm{w} / \mathrm{v})$ sodium azide containing $0.3 \%$ hydrogen peroxide $(\mathrm{v} / \mathrm{v})$ for 10 minutes. After washing in PBS, smears were incubated in $1 \mu \mathrm{g} / \mathrm{ml}$ proteinase $\mathrm{K}$ (Boehringer, Germany) in PBS for 15 minutes at $37^{\circ} \mathrm{C}$, washed in PBS, postfixed in $4 \%$ paraformaldehyde for five minutes, washed in $\mathrm{PBS} /$ glycine, PBS, and air dried at $37^{\circ} \mathrm{C}$. Smears prepared in this way were processed the same day.

CaSki, HeLa 229, and SiHa cells

Cells were obtained from the ATCC (USA) and grown in RPMI 1640 medium supplemented with $10 \%$ fetal calf serum (FCS) and L-glutamine. ${ }^{18}$ All three cell lines were grown to confluence and cells harvested by treatment with trypsin-EDTA solution (Gibco, UK). After washing in PBS, cells were fixed in suspension in methanol/acetic acid ( 3 in $1, v / v)$ and stored at $-20^{\circ} \mathrm{C}^{21}$ When required, these cells were centrifuged at $600 \times g$ for five minutes, resuspended in a small volume of fresh cold methanol/acetic acid, spotted onto four spot multiwell slides (Hendley, Essex), dried at $37^{\circ} \mathrm{C}$ and treated as for routine smears. The peroxidase blocking step is not required for analysis of epithelial cell-lines.

NON-ISOTOPIC IN SITU HYBRIDISATION (NISH) HPV6, 11, 16, 18, 31, and 33 probes labelled with either biotin or digoxigenin were hybridised to cervical smears pretreated as above. Cocktails of these genomic probes were used for the analysis of routine cervical smears (see Results). Cells of $\mathrm{CaSki}$, SiHa (which contain integrated HPV16) and HeLa cells (which contain integrated HPV18) were hybridised with HPV16 and 18 individually. The hybridisation cocktail contained the following: $50 \%$ formamide, $5 \%$ dextran sulphate, $300 \mathrm{mM}$ $\mathrm{NaCl}, 30 \mathrm{mM}$ sodium citrate, $50 \mathrm{mM}$ Tris $\mathrm{HCl}, \mathrm{pH} 7 \cdot 4,0 \cdot 1 \%(\mathrm{w} / \mathrm{v})$ sodium pyrophosphate, $0.2 \% \quad(\mathrm{w} / \mathrm{v})$ polyvinylpyrrolidine (molecular weight 40000$), 0.2 \%$ (w/v) Ficoll (molecular weight 400000 ), 5 mM EDTA, $200 \mathrm{ng} / \mu \mathrm{l}$ sheared human DNA and $2 \mathrm{ng} / \mu \mathrm{l}$ of each labelled probe. An aliquot of hybridisation cocktail $(50 \mu \mathrm{l})$ was added to each smear and covered with a $22 \times 50 \mathrm{~mm}$ coverslip. Cells and probes were denatured simultaneously in moist Terasaki plates at $95^{\circ} \mathrm{C}$ for 15 minutes and hybridised at $42^{\circ} \mathrm{C}$ for two hours. After hybridisation, slides were washed in $4 \times$ (SSC) standard saline citrate twice at $22^{\circ} \mathrm{C}$, then $50 \mathrm{mM}$ TRIS- $\mathrm{HCl}$, pH $7 \cdot 2$, $100 \mathrm{mM} \mathrm{NaCl}$ (TBS) containing 3\% (w/v) bovine serum albumin and $0.05 \%(v / v)$ Triton $\mathrm{X}-100$ (TBT) for 10 minutes.

PROBE DETECTION

All antibody/avidin incubations were carried out at room temperature for $\mathbf{3 0}$ minutes unless otherwise stated.

Biotinylated probes

Smears were incubated in either avidin alkaline phosphatase (Dako, UK) diluted 1 in 50 or avidin peroxidase (Dako, UK) diluted 1 in 75 in TBT containing $5 \%(\mathrm{w} / \mathrm{v})$ non-fat milk
(Cadbury, UK). After washing for 10 minutes in TBS, the signal was developed using either nitroblue tetrazolium (NBT)/5-bromo-4chloro-3-indolyl phosphate (BCIP) for alkaline phosphatase detection or aminoethylcarbazole (AEC; Zymed, USA) for peroxidase detection. ${ }^{18}$

\section{Digoxigenin labelled probes}

The detection procedures consisted of three or five steps.

Three step detection Smears were incubated in monoclonal anti-digoxin (Sigma, UK) diluted 1 in 10000 in TBT followed by biotinylated rabbit anti mouse $\left[\mathrm{F}(\mathrm{ab})_{2}\right.$ fragment] diluted 1 in 200 in TBT and then by avidin peroxidase diluted 1 in 75 in TBT containing $5 \%(w / v)$ non-fat milk. The signal was developed using AEC as described. ${ }^{18}$

Five step detection After incubation in monoclonal anti-digoxin and biotinylated rabbit anti mouse $\left[\mathrm{F}(\mathrm{ab})_{2}\right.$ fragment] as described above, further incubation was carried out in monoclonal anti-biotin diluted 1 in 50 in TBT followed by biotinylated rabbit anti mouse $\left[\mathrm{F}(\mathrm{ab})_{2}\right.$ fragment]. These latter two incubations were carried out for 10 minutes and followed by avidin peroxidase diluted 1 in 75 in TBT containing $5 \%(w / v)$ non-fat milk. The signal was developed using AEC as described. ${ }^{18}$

All slides stained using AEC were counterstained progressively with haematoxylin for approximately 10-15 seconds. All slides were mounted in glycerol jelly.

\section{CONTROLS}

Negative controls were: CaSki and SiHa cells hybridised with HPV18 and HeLa cells with HPV 16; omission of probe in the hybridisation mix; and hybridisation with HPV2 (a cutaneous HPV type). Positive controls were: CaSki cells hybridised with HPV16 with each batch of cervical smears and hybridisation of smears with total human DNA.

\section{Results}

CULTURED CELLS

CaSki, HeLa and SiHa cells were treated in the same way as cervical smears to estimate the sensitivity of the procedures used in this study. It has been shown that the single step procedures used for biotin and digoxigenin detection have a sensitivity of at least $30-40$ HPV copies per cell. ${ }^{18}$ The amplification of digoxigenin detection using monoclonal antidigoxin enhances the sensitivity and flexibility of probe detection: specifically, the three step detection of digoxigenin has been estimated to have a sensitivity of approximately 2.5-12 copies of HPV per cell. ${ }^{16}$ This amplification was extended in this study using the five step protocol with peroxidase $\mathrm{AEC} / \mathrm{H}_{2} \mathrm{O}_{2}$ for digoxigenin detection. This procedure detected HPV16 in SiHa cells, which contain only 1-2 copies of HPV16 integrated at position 13q21-31 (fig 1). ${ }^{22}$ The signal is present in two morphologically similar but discrete foci. These may represent HPV sequences integrated into both copies of chromosome 13, 
Figure 1 HPV16

detection in SiHa cells.

Two discrete foci of signal of similar morphology can be seen within a single nucleus. the remainder of the study and hybridised with a cocktail of HPV16, 18, 31, and 33 probes.

The main initial technical problem in the analysis of routine cervical smears hybridised with a cocktail of biotinylated HPV probes was intense background staining (fig 2A). By incorporating large molecular weight polymers in the hybridisation cocktail, this background staining was reduced but not abolished. For single nucleic acid detection, digoxigenin labelled probes gave lower background staining than biotinylated probes and peroxidase based systems produced cleaner results than alkaline phosphatase. However, the single most important component was the inhibition of non-specific avidin binding by the use of nonfat milk (table 2, fig 2 ). The cellular morphology is clarified by haematoxylin counterstaining (fig 2B). Further amplification using the five step method gave unacceptable background staining despite the incorporation of all blocking steps in table 2 (data not shown). This background was reduced by lowering the concentration of each probe in the hybridisation reaction. However, the sensitivity of probe detection is dependent on probe concentration (see above) and hence reduction of the probe concentration below $2 \mathrm{ng} / \mu \mathrm{l}$ negates the advantage of using the five step system.

The optimum system for HPV detection in routine cervical smears is therefore the three step peroxidase based detection of digoxigenin labelled probes with haematoxylin counterstaining (fig 2B). investigated to assess the possibility of reducing individual probe concentrations when probe cocktails were used in the analysis of cervical smears (see below). Hybridisation of CaSki cells with digoxigenin labelled HPV16 followed by detection using the three step procedure with AEC as substrate was carried out at probe concentrations of $0 \cdot 1,0.5,1,2,4$, and $8 \mathrm{ng} / \mu \mathrm{l}$. Reduction in probe concentration below $2 \mathrm{ng} / \mu \mathrm{l}$ led to a reduction in sensitivity as judged by the median number of signals obtained per CaSki cells nucleus (table 1).

\section{CERVICAL SMEARS}

\section{Methodological development}

Initially, the single step detection methods were employed on routine cervical smears to evaluate the pretreatment and hybridisation methods. By using total human DNA as a probe, the effect of aldehyde fixation was assessed: as was noted previously for HPV16 detection in CaSki cells, ${ }^{18}$ the signal obtained in routine smears was considerably stronger in aldehyde fixed smears than in those fixed only in methanol/acetic acid (data not shown). Aldehyde fixed smears were therefore used in

Table 1 Sensitivity of HPV16 detection in CaSki cells

\begin{tabular}{lccc}
\hline & \multicolumn{3}{c}{ Median signal } \\
\cline { 2 - 4 } Applied probe concentration $(n g / \mu l)$ & No & Range & $n$ \\
\hline $0 \cdot 1$ & 1 & 0 & \\
$0 \cdot 5$ & 6 & $(2-1)$ & 123 \\
1 & 11 & $(3-20)$ & 111 \\
2 & 10 & $(3-20)$ & 106 \\
4 & 11 & $(5-20)$ & 104 \\
8 & & & \\
\hline
\end{tabular}

\section{Application to routine cervical smears}

Having established the most appropriate method, this technique was applied to 53 cervical smears collected in the routine way from women attending a sexually transmitted disease clinic. The smears used for NISH analysis were collected by a separate pass of the spatula. The cytopathological diagnoses made on the Papinacolau-stained smears were compared with the results of NISH analysis (table 3, fig 3). All epithelial cells which contained a NISH signal demonstrated at least minor morphological abnormality (see Discussion). The positive and negative controls incorporated in each batch gave the appropriate result-that is multiple nuclear HPV16 signals were obtained in CaSki cells and every nucleus in the smear was stained after hybridisation with a probe for total human DNA.

\section{Discussion}

The object of this study was to develop methods of high sensitivity and resolution for the detection of human papillomavirus DNA sequences in routine cervical smears and to apply them to the analysis of a group of women attending a sexually transmitted disease clinic. HPV6/11 infection has been associated with low grade, and HPV16/18 and related viral types with high grade, squamous cervical lesions. ${ }^{23}$ It is therefore of potential clinical importance to determine by molecular means the viral type present in cervical epithelial cells. Although this can be performed by a variety of methods involving the extraction of DNA from 


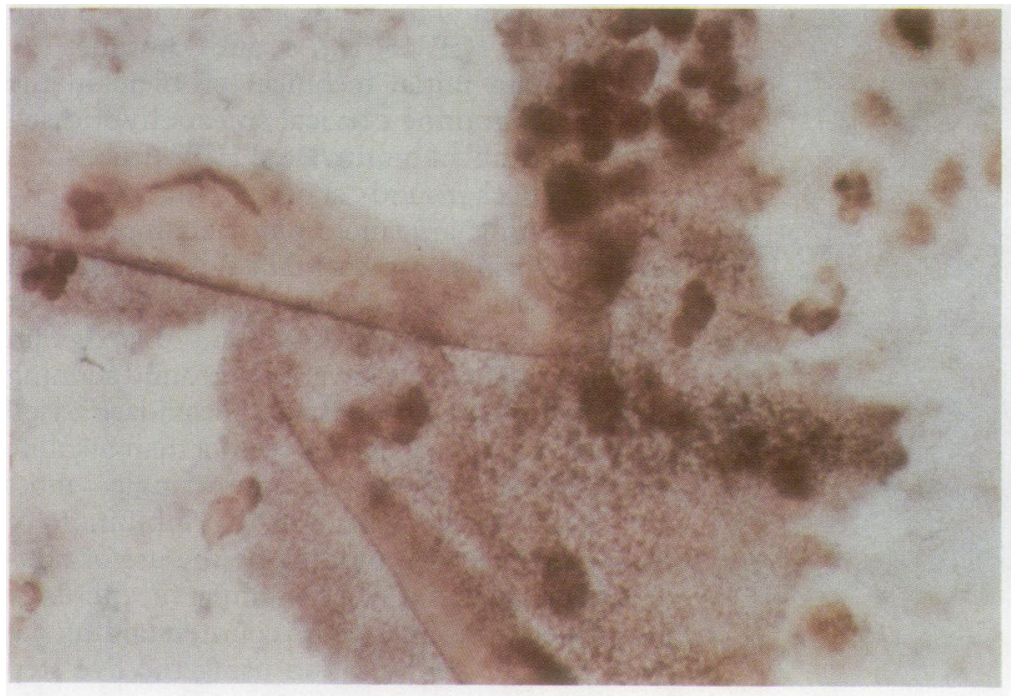

(A)

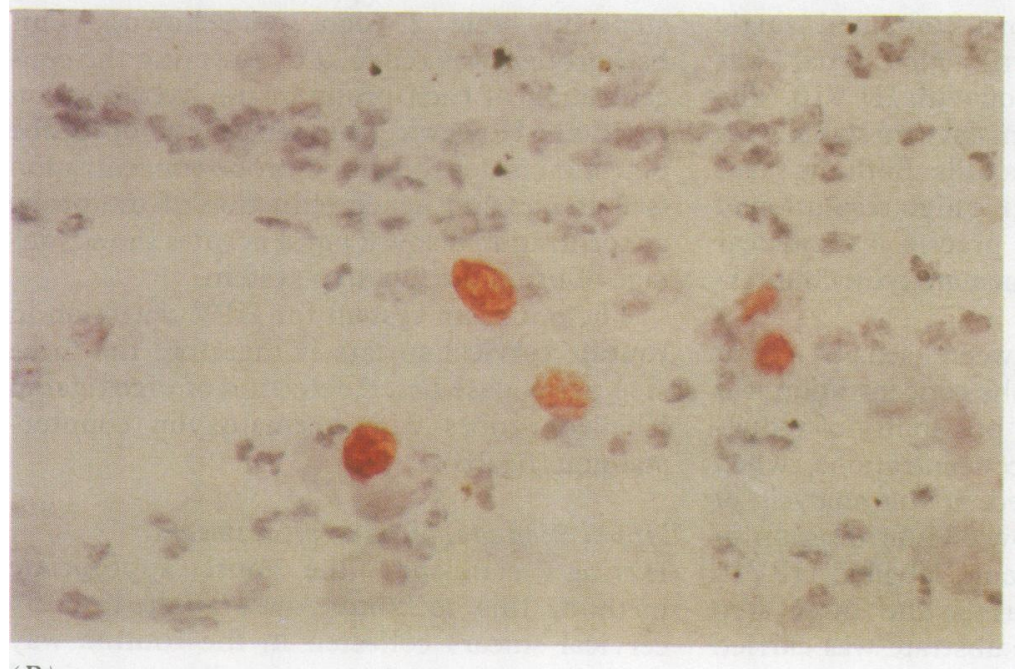

(B)

Figure $2 H P V$ detection in routine cervical smears. $(A)$ No blocking procedures were used and a biotinylated cocktail of HPV probes was detected using avidin alkaline phosphatase and NBT/BCIP. All cellular and non-cellular components of the smear are labelled, typical of biotinylated probes in the absence of blocking agents. (B) All blocking procedures were used and a digoxigenin labelled HPV probe cocktail detected using the three step peroxidase AEC method. A clear nuclear red signal is coupled with good morphological definition. An intranuclear red signal is present in several abnormal nuclei.

exfoliated cervical cells (Southern blotting, ${ }^{24}$ filter in situ hybridisation, ${ }^{5}$ PCR amplification ${ }^{9}$ ), only in situ hybridisation can demonstrate HPV sequences in intact nuclei. Moreover, as cervical smears taken by general practitioners are used as the means of cervical screening in the United Kingdom, the ability to analyse these samples directly would not require changes in clinical practice.

Table 2 Reduction of non-specific staining in routine cervical smears

Hybridization solution

Digoxigenin labelled probes

Sodium pyrophosphate, polyvinylpyrrolidone (molecular weight 40000 ), Ficoll (molecular weight 400000 )

Sheared human DNA in 100-1000 fold excess over probe

Detection procedure

Block non-specific avidin binding using modified avidin in non-fat milk

Use peroxidase based system rather than alkaline phosphatase

Fig 2 compares the results with biotin and digoxigenin labelled probes with and without the blocking procedures.
Table 3 Comparison of the detection of HPV16, 18, 31, and 33 by NISH in routine cervical smears with cytopathological diagnosis

\begin{tabular}{llll}
\hline \multicolumn{4}{l}{ Cytopathological diagnosis } \\
\cline { 2 - 4 } NISH & $\begin{array}{l}\text { Normal } \\
n=24\end{array} \quad \begin{array}{l}\text { Wart virus infection } \\
n=17\end{array}$ & $\begin{array}{l}\text { CIN1 + WV1 } \\
n=12\end{array}$ \\
\hline Negative & $16(66 \cdot 7 \%)$ & $6(35 \cdot 3 \%)$ & $6(25 \%)$ \\
Positive & $8(33 \cdot 3 \%)$ & $11(64 \cdot 7 \%)$ & $9(75 \%)$ \\
\hline
\end{tabular}

$\mathrm{CIN}$, cervical intraepithelial neoplasia.

The detection of HPV DNA in routine cervical smears poses several problems. Firstly, only one smear is taken and this is required for cytopathological diagnosis. It is thus impossible to perform controls on material from the same patient. However, the use of HPV containing cell lines and hybridisation of cervical smears with a probe to total human DNA allowed assessment of each experiment. Secondly, cervical smears contain a variable amount of mucin and may be contaminated with bacteria, fungi, and protozoa. This may lead to technical problems, particularly high background staining. As cervical smears are collected from patients randomly with respect to their menstrual cycle and by different practitioners with consequent variation in smear quality and fixation, it was necessary to develop a method with the following properties: minimal loss of material, no reliance on quality of initial fixation, low background staining, and inhibition of endogenous neutrophil peroxidase. Optimisation of fixation and unmasking conditions showed that aldehyde fixation followed by limited proteinase $\mathrm{K}$ digestion produced superior results to direct analysis of ethanol fixed smears using digoxigenin labelled total human DNA as probe. This is consistent with results obtained using CaSki cells. ${ }^{18}$ The combination of sodium azide and hydrogen peroxide prior to nucleic acid unmasking produced effective inhibition of endogenous peroxidase, which is particularly important in the analysis of smears containing large numbers of inflammatory cells. Postfixation of smears in aldehyde minimised the loss of cellular material, particularly as routine smears are not collected on silane-coated slides. ${ }^{25}$ Hybridisation in the presence of excess human DNA, polyvinylpyrrolidine, and Ficoll reduced non-specific probe binding to noncellular components of the smear. High background staining due to deposition of NBT/ BCIP derived product over mucin rich areas was inhibited by blocking non-specific avidin binding by both the use of modified avidin and incubation in non-fat milk. The most effective individual step in the reduction of background staining was incubation in the avidin conjugate in the presence of non-fat milk. This suggests that the majority of the background staining observed was due to non-specific binding of avidin to non-cellular components of the smear.

For routine nucleic acid detection, the most effective protocols were those involving peroxidase based detection of digoxigenin labelled probes. Amplification of the detection 


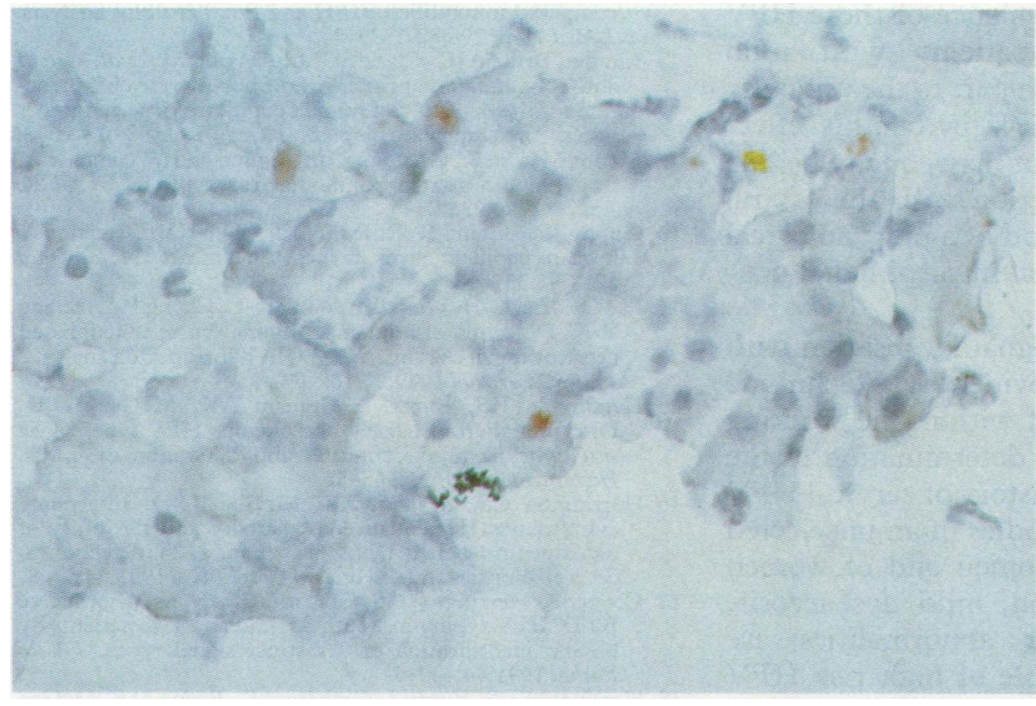

Figure 3 HPV 16, 18, 31, and 33 probes were hybridised to a routine cervical smear. Note the presence of an intranuclear red signal in cells within a cluster of epithelial cells.

of these probes enabled HPV16 to be detected in $\mathrm{SiHa}$ cells. However, application of this system to the detection of probe cocktails in routine cervical smears produced unacceptable and variable background staining, due to the high total probe concentration. However, reduction in probe concentration leads to a marked reduction in sensitivity, which is predictable as the in situ hybridisation reaction is carried out with excess probe. The three step digoxigenin detection system was the most routinely applicable, giving the most reproducible signal with high sensitivity (approximately 2.5-12 HPV copies per cell), ${ }^{16}$ high resolution, and low background staining. The combination of this protocol with haematoxylin counterstaining provides good morphological contrast and is therefore of potential routine use.

This methodology was applied to cervical smears collected from a sexually transmitted disease clinic as there was likely to be a high prevalence of HPV infection amongst these patients. This analysis showed the presence of "high risk" sequences (HPV16, 18, 31, and 33) in $33.3 \%$ of cases (24) in which no cytological abnormality was demonstrated on a parallel Papinacolau-stained smear. One possible explanation for these findings is that the cervical sampling of the two smears differs, with the second smear containing cells shed from an abnormal area not sampled in the first. This situation is known to arise with moderate frequency. ${ }^{26}$ Careful analysis of the morphological features in these cases showed that the positive cells were not morphologically normal, although the abnormalities present were not sufficient to warrant a diagnosis of wart virus infection or dyskaryosis (fig 3). These would be classified as borderline nuclear abnormalities or inflammatory changes by routine cytopathological criteria. In addition, many positive cells were present in large clusters of epithelial cells where morphological assessment is difficult and any abnormalities present would not necessarily have been recognised on routine Papinacolau screening. No evidence was found for the presence of HPV sequences in morphologically normal epithelial cells and, if this occurs, it is likely to be an uncommon event. In this study, the presence of HPV sequences was always associated with at least minor morphological abnormality. This does not exclude the possibility of HPV infection of morphologically normal epithelial cells, as the sensitivity of the technique is not sufficient to detect fewer than $2 \cdot 5-12$ copies of HPV per cell, but these observations are consistent with the fact that HPV sequences have never been shown in normal epithelial cells in cervical biopsies by in situ hybridisation. ${ }^{1727}$ Moreover, a study in which HPV sequences were detected by PCR amplification and compared with the morphology of parallel sections showed that there was absolute concordance between morphological abnormality and the presence of HPV: no HPV sequences were shown in normal cervical epithelium, even directly adjacent to a focus of HPV infection. ${ }^{28}$ However, irrespective of the reason for the discrepancy between cytopathology and NISH, HPV infection was shown in one third of patients with no abnormality on routine cervical screening. These data concur with those derived from a separate patient cohort from the same clinic, analysed by dual in situ hybridisation, in which $25 \%$ of parallel smears $(n=128)$ from patients with a Papinacolau smear showing no abnormality contained high risk HPV sequences. ${ }^{29}$ The technique used in the latter study had a lower sensitivity (approximately 40-50 copies per cell) than that used here. The possibility that the high prevalence of HPV in women with parallel Papinacolau stained smears showing no abnormality is due at least in part to sampling error may explain the wide variation in estimates of prevalence of HPV sequences in the normal population. ${ }^{4-12}$ The application of this technique to a large unselected population of patients will permit assessment of the true prevalence of HPV infection of normal epithelial cells and its role in the natural history of HPV infection.

The demonstration of HPV sequences by molecular techniques in the absence of clinical or cytopathological abnormality has been defined clinically as latent HPV infection. ${ }^{3}$ Since all HPV positive cells in this study showed minor morphological abnormalities and HPV sequences were not found in morphologically normal cells, it would be wise to use the term occult rather than latent HPV infection: the term latency has a different biological implication.

The analysis of smears with morphological evidence of wart virus infection showed the presence of high risk HPV sequences in morphologically abnormal cells in $64.7 \%$ of cases (17). The high prevalence of cases infected with high risk types is at variance with the commonly held view that morphological evidence of wart virus infection is indicative of HPV6, 11-that is low risk infection. These data agree with those from a study of a separate cohort of patients from the same clinic in which $58 \%$ of cases $(50)$ were infected with high risk 
types. ${ }^{29}$ The similar prevalence of these HPV types $(75 \%, 12)$ in patients with mild dyskaryosis may be due in part to the difficulty in distinguishing the HPV cytopathic effect from mild dyskaryosis but may equally be due to pure wart virus infection with these viral types representing one end of a morphological spectrum through cervical intraepithelial neoplasia to invasive cancer.

The combination of signal localisation with cellular morphology, provided by a technique which can be performed within one working day, will permit routine determination of the prevalence and natural history of cervical HPV infection. Prospective studies of an unselected normal population of women and of women with wart virus infection, mild dyskaryosis, and borderline nuclear abnormalities are required to define the role of high risk HPV infection in the aetiology of CIN. Borderline changes are a major clinical problem and in this clinical school constituted approximately 9000 of a total of 65000 cervical smears screened in 1990.

CSH held a Cancer Research Campaign (UK) Clinical Research Fellowship and is a Junior Research Fellow, Green College, Oxford. This work was supported by grants to J O'D McG from the Cancer Research Campaign (UK). We are grateful to Drs G Orth and A Lorincz for the HPV 31 and 33 probes.

1 Matlashewski $\mathrm{G}$. The cell biology of human papillomavirus transformed cells. Anticancer Res 1989;9:1447-556.

2 De Villiers E-M. Heterogeneity of the human papilloma virus group. $J$ Virol 1989;63:4898-903.

3 Syrjänen K. Natural history of genital HPV infections. Papillomavirus Rep 1990;1(4):1-4.

4 Beyer-Finkler E, Pfister H, Girardi F. Anti-contamination primers to improve specificity of polymerase chain reaction in human papillomavirus screening. Lancet 1990; 1289-90.

5 Wagner D, Ikenberg H, Boehm N, Gissmann L. Identification of human papillomavirus in cervical swabs by deoxyribonucleic acid in situ hybridization. Obstet Gynaecol 1984;64:767-72.

6 Lorincz AT, Temple GF, Patterson JA, Jenson AB, Kurman RJ, Lancaster W. Correlation of cellular atypia and human papillomavirus deoxyribonucleic acid sequences in exfoliated cells of the uterine cervix. Obste Gynaecol 1986;68:508-12.

7 Gergely L, Czegledy J, Hernady Z. Human papillomavirus frequency in normal tissue. Lancet 1987;ii:513.

8 DeVilliers E-M, Schneider A, Miklaw H, et al. Human papillomavirus infection of women with and withou abnormal cervical cytology. Lancet 1987;ii:703-6.

9 Young LS, Bevan IS, Johnson MA, et al. The polymerase chain reaction: a new epidemiological tool for investigating cervical human papillomavirus infection. Br Med $J$ 1989;298:14-8.

10 Melchers W van den Brule A, Walboomers J, et al. Increased detection rate of human papillomaviruses in cervical scrapes by the polymerase chain reaction as compared to modified FISH and Southern blot analysis. J Med Virol 1989;27:329-35.

11 van den Brule AJC, Claas ECJ, du Maine M, et al. Use of anti-contamination primers in the polymerase chain reaction for the detection of human papillomavirus genotypes in cervical scrapes and biopsies. JMed Virol 1989;29:20-7.

12 Manos M, Lee K, Greer C, Christopherson R, Pearson TA. Looking for human papillomavirus type 16 by PCR. Lancet 1990;335:734

13 Gupta JW, Gupta PK, Rosenhein N, Shah KV. Detection of human papillomavirus in cervical smears. Acta Cytol 1987;31:387-96.

14 Pao CC, Lai C-H, Wu S-Y, Young K-C, Chang P-L, Soong $\mathrm{Y}-\mathrm{K}$. Detection of human papillomaviruses in exfoliated cervicovaginal cells by in situ DNA hybridization analysis. J Clin Microbiol 1989;27:168-73.

15 Herrington CS, Burns J, Graham AK, McGee JO'D. Discrimination of closely homologous HPV types by in situ hybridization: definition and derivation of TM's. Histochem J 1990;22:545-54.

16 Herrington CS, Graham AK, McGee JO'D. Interphase cytogenetics III: enhanced sensitivity and flexibility of digoxigenin labelled DNA probes for HPV detection in cervical biopsies and cell lines. J Clin Pathol 1991;44:33-8.

17 Cooper K, Herrington CS, Graham AK, Evans MF, McGee JO'D. HPV typing in South African and UK patients by NISH: identification of 3 distinct signal types. $J$ Clin Pathol 1991;44:400-5.

18 Herrington CS, Burns J, Graham AK, Evans MF, McGee JO'D. Interphase cytogenetics using biotin and digoxigenin labelled probes I: relative sensitivity of both reporgenin labelled probes 1 : relative sensitivity of both reporters for detection of

19 Burns J, Redfern DRM, Esiri MM, McGee JO'D. Human and viral gene detection in routine paraffin embedded and viral gene detection in routine paraffin embedded tissue by in situ hybridization with biotinylated probes:
viral localisation in herpes encephalitis. J Clin Pathol viral localisation

20 Coleman DV, Evans DMD. Biopsy pathology and cytology of the cervix. London: Chapman and Hall, 1988.

21 Herrington CS, Burns J, Graham AK, Bhatt B, McGee JO'D. Interphase cytogenetics using biotin and digoxigenin labelled probes II: simultaneous detection of two nucleic acid species in individual nuclei. $J$ Clin Pathol 1989;42:601-6.

22 Mincheva A, Gissmann L, Zur Hausen H. Chromosomal integration sites of human papillomavirus DNA in three cervical cancer cell lines mapped by in situ hybridization. Med Microbiol Immunol 1987;176:245-56.

23 Syriänen KJ. Papillomavirus infections and cancer. In: Syrjänen K, Gissmann L, Koss LG, eds. Papillomavirus and human disease. Berlin: Springer-Verlag, 1987: 467-504.

24 Toon PG, Arrand JR, Wilson LP, Sharp DS. Human papillomavirus infection of the uterine cervix of women without cytological signs of neoplasia. $\mathrm{Br}$ Med J 1986; 293:1261-4.

25 Burns J, Graham AK, Frank C, Fleming KA, Evans MF, McGee JO'D. Detection of low copy human papilloma virus DNA and mRNA in routine paraffin sections of cervix by non-isotopic in situ hybridization. J Clin Pathol 1987;40:858-64.

26 Syriänen S, Saastamoinen J, Chang F, Ji H, Syrjänen K. Colposcopy, punch biopsy, in situ DNA hybridization and the polymerase chain reaction in searching for genital the polymerase chain reaction in searching for genital human papillomavirus (HPV) infections in women
normal PAP smears. J Med Virol 1990;31:259-66.

27 Crum CP, Nuovo GJ. Latent or Occult HPV infection. In: Genital papillomaviruses and related neoplasms. New York: Raven Press, 1991:88-105.

28 Cornelissen MTE, Van den Tweel JG, Struyk APHB, et al. Localisation of human papillomavirus type 16 DNA using the polymerase chain reaction in the cervix uteri of women with cervical intraepithelial neoplasia. J Gen Virol 1989;70:25-2562.

29 Herrington CS, Troncone G, Evans M, McGee JO'D. Screening for high and low risk human papillomavirus (HPV) types in single routine cervical smears by nonisotopic in situ hybridization (NISH). Cytopathology (In isotopic
press). 